a single blood dot by ordinary ophthalmoscopy of these patients. By microscopy of the retina it is also rather unusual to find microaneurysms. These facts combined with the observation that fluorescent dots disappear quickly during treatment of the hypertension (Hodge and Dollery, 1964) indicate that the fluorescent dots are due to exudates which are not ophthalmoscopically visible.

\section{Summary}

Some of the results from fluoresceinretinography of diabetic patients are demonstrated, and the interpretation of some of the observations is discussed. It is concluded that most of the small fluorescent dots which appear in diabetics and hypertensive patients can be interpreted as small exudates rather than microaneurysms.

\section{REFERENCES}

Dollery, C. T., Hodge, J. V., and Engel, M. (1962). Brit. med. F., 2,

Esmann, V., Lundbæk, K., and Madsen, P. H. (1963). Acta med. scand., 174,375 .

Friedenwald, J. S. (1950). Amer. 7. Ophthal., 33, 1187.

Hodge, J. V., and Dollery, C. T. (1964). Quart. F. Med., 33, 117.

Hodge, J. V., and Dollery, C. T. (1964). Quart. F. Mede, 33,

Novotny, H. R., and Alvis, D. L.i. (1961). Circulation, 24, 82. Fraser, R. (1964). Brit. med. $\dot{y}_{.2}, 1,811$.

Personal communication, Jensen, H. J., Arhus Kommunehospital.

\title{
Galvanic Stimulation of the Tongue as a Prognostic Index in Bell's Palsy
}

\author{
O. A. PEIRIS, * M.D., M.R.C.P., M.R.C.P.ED. ; D. W. MILES,* M.B., CH.B., B.SC., M.R.C.P.
}

Brit. med. F., 1965, 2, 1162-1163

Bell's palsy is one of the commonest lesions seen in neurological practice. Between $35 \%$ and $45 \%$ of patients affected show evidence of denervation, which may result in troublesome sequelae such as continuing muscle-weakness, "associated movements," and "crocodile tears" (Taverner, 1955, 1959). The correct management of such patients depends on the early detection of denervation. Electrical conduction studies enable a firm prognosis to be made seven days from the onset of the lesion (Langworth and Taverner, 1963). The present report concerns the value of anodal galvanic stimulation of the anterior two-thirds of the tongue in making an even earlier prognosis in Bell's palsy.

\section{Material and Methods}

Bell's palsy was diagnosed according to the following criteria (Taverner, 1955): (1) the sudden onset of complete or partial paralysis of the muscles of expression on one side of the face ; (2) the absence of any symptoms or signs of any other disease of the central nervous system; (3) the absence of any symptoms or signs of any disease of the ear or posterior fossa ; and (4) the absence of herpetic vesicles.

Studies were made of 69 cases, the method of electrogustometry (Krarup, 1958a) being used. A 120-volt dry battery is connected through a circuit which is shown in the Diagram. The cathode was held firmly by the patient and the anode was applied to the tongue. This stimulating electrode was a circular disk $7 \mathrm{~mm}$. in diameter, made of platinum. The stimulus was applied to the lateral aspect of the tongue over the area that lies against the canine tooth when the tongue is placed on the floor of the mouth. The electrode was applied to the normal side first and the stimulus strength was increased gradually until the patient was able to appreciate a distinct acidic taste. In some cases it was necessary to do this a few times so that the patient understood what was required. The same procedure was then repeated on the side showing the paralysis and any alteration in threshold was noted. In $90 \%$ of cases the patients could appreciate stimuli of $30 \mu \AA$ or less on the normal side. In the remaining $10 \%$ the threshold on the normal side was raised above $30 \mu \AA$, and this was associated with heavy smoking, coated tongues, or low intelligence. Since a comparison of the

* Department of Medicine, University of Leeds. two sides was the essential observation no regard was paid to the threshold level on the normal side provided that this could be recorded. The disparity in threshold on the two sides was recorded, and the values thus obtained were classified into three groups in the following manner: (1) those patients with an elevation of threshold to more than $100 \mu \AA$ above the normal side; (2) those in whom the threshold was at least $10 \mu \AA$ higher than on the normal side; and (3) those with a normal response; here there was no measurable difference in the thresholds on the two sides.

Clinical assessment of function in the face was estimated in terms of a percentage of normal function in the orbicularis oris, the orbicularis oculi, and the frontalis muscles. Electromyography and facial-nerve-conduction studies were done in every case. All patients in the series were seen at the end of three or more months in order to assess the outcome of the lesion. In this follow-up special care was taken to note the presence of associated movements in the face and fibrillation and "blink-burst" activity in the electromyogram. The pre-

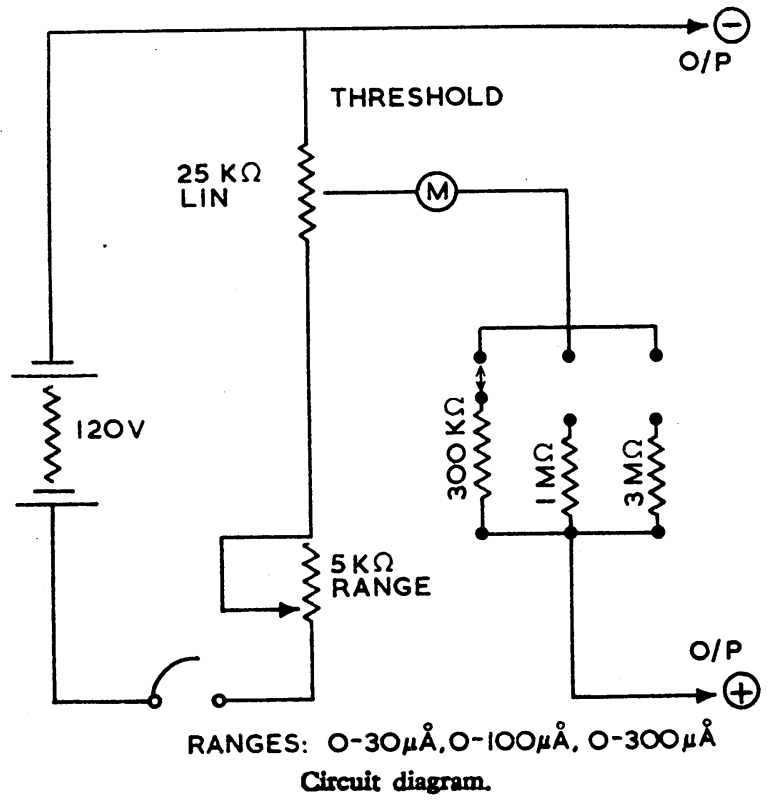


sence of these was taken to indicate that some denervation-that is, Wallerian degeneration of fibres in the facial nervehad taken place (Denny-Brown and Pennybacker, 1938; Taverner, 1955).

These findings were correlated with the alteration in threshold to galvanic stimulation.

\section{Results}

The patients examined were divided into two groups as shown in the Table. Group 1 consisted of patients seen within 14 days of the onset of the paralysis, and group 2 consisted of those seen more than 14 days from the onset. Each group was arranged on the basis of clinical, electromyographic, and nerve-conduction studies-the criteria of Langworth and Taverner (1963) being used-into those with complete denervation, partial denervation, or conduction block.

Cases seen within 14 days of onset (Group 1), and more than 14 days after onset (Group 2)

\begin{tabular}{|c|c|c|c|c|c|c|}
\hline & \multicolumn{3}{|c|}{$\begin{array}{c}\text { Group 1 } \\
\text { Galvanic Response }\end{array}$} & \multicolumn{3}{|c|}{$\begin{array}{c}\text { Group 2 } \\
\text { Galvanic Response }\end{array}$} \\
\hline & \multirow{2}{*}{ Normal } & \multicolumn{2}{|c|}{ Abnormal } & \multirow{2}{*}{ Normal } & \multicolumn{2}{|c|}{ Abnormal } \\
\hline & & $>10 \mu \AA$ & $>100 \mu \AA$ & & $10 \mu \AA$ & $100 \mu \AA$ \\
\hline $\begin{array}{l}\text { Denervation }\left\{\begin{array}{l}\text { Complete } \\
\text { Partial } \\
\text { Conduction block }\end{array} \text {.. }\right.\end{array}$ & $\begin{array}{r}0 \\
1 \\
21\end{array}$ & $\begin{array}{l}1 \\
8 \\
0\end{array}$ & $\begin{array}{l}9 \\
2 \\
0\end{array}$ & $\begin{array}{r}5 \\
10 \\
5\end{array}$ & $\begin{array}{l}2 \\
0 \\
0\end{array}$ & $\begin{array}{l}4 \\
1 \\
0\end{array}$ \\
\hline
\end{tabular}

From the Table it can be seen that within the first 14 days (group 1) all the patients who eventually made a complete recovery from their Bell's palsy had a normal galvanic response. In those who made an incomplete recovery and were left with the sequelae of a more severe attack an abnormal galvanic response was obtained in 20 out of 21 . Further subdivision of this group shows that nine out of the 10 patients who developed complete denervation had a galvanic response greater than $100 \mu \AA$ above the normal side.

When patients were seen after 14 days from the onset (group 2) the results show that those who eventually made a complete recovery had a normal galvanic response, as did 15 of the 22 patients who had a more severe attack.

\section{Discussion}

Langworth and Taverner (1963) demonstrated that patients who denervate completely lose electrical conduction in the facial kerve after five to seven days. Their ultimate recovery is always poor and cross-innervation is inevitable. Patients with partial denervation always retain conduction in the facial nerve, though the latency of the action potential may be prolonged and the response is smaller in amplitude than normal. These patients may make a good functional recovery, though some cross-innervation inevitably occurs, and therefore associated movements-for example, twitching of the angle of the mouth on blinking - are always noted in the face. Patients showing no evidence of denervation have normal conduction throughout their illness and final recovery is always complete.

Many authors (Park and Watkins, 1949 ; Garland, 1953 ; Taverner, 1955 ; Krarup, 1958a ; Sullivan and Smith, 1959) concluded that the loss of taste in Bell's palsy had no bearing on the final outcome of the lesion, though Krarup was cautious in stating that investigations on numbers of early cases might possibly give a solution to the problem. This series shows clearly that the outcome of Bell's palsy can be predicted with considerable accuracy at the onset of the lesion. An alteration in the galvanic threshold was associated with evidence of denervation in all our cases, and there is an association between the threshold and the severity of the lesion.

In this series there was one patient in whom the galvanic response was normal, though partial denervation occurred. This could have been due either to an unusually early recovery of taste or to the fact that taste was carried by an alternative pathway. It has been shown that taste from the anterior twothirds of the tongue may be conveyed by a pathway other than the chorda tympani, such as the greater superficial petrosal nerve (Cushing, 1903 ; Moruzi and Lechintski, 1938 ; Schwartz and Weddell, 1938).

The patients seen more than 14 days from the onset show a less complete correlation. In 15 of the 22 who showed some denervation there was no alteration in taste threshold. This presumably means that in cases of Bell's palsy the sensation of taste recovers long before somatic function recovers in the seventh nerve. This view accords with the observations of Krarup (1958b), who noted the same feature.

Nerve-conduction studies are usually normal in cases of Bell's palsy when the patient is seen soon after the onset of the paralysis. Careful follow-up studies are required to make an accurate assessment (Langworth and Taverner, 1963). The great advantage in using galvanic threshold determination in prognosis is that it enables the prognosis to be made before facial-nerve conduction is affected. Of the 21 patients who showed evidence of denervation nine had normal conduction in the facial nerve within six days of the onset of paralysis, at a time when the results of galvanic stimulation of the tongue were abnormal.

The other advantages of the method are that the apparatus used is very cheap, simple, and easily portable, and the measurement causes no discomfort to the patient.

It must be noted that this method is applicable only to cases of Bell's palsy and not to other types of facial paralysis, and cannot be used in children or the unintelligent.

\section{Summary}

Sixty-nine patients with Bell's palsy were examined by the method of electrogustometry. Forty-two of these were seen within 14 days of the onset of the lesion. Of this group 21 patients recovered completely, and in all of these there was no detectable alteration in the response to galvanic stimulation on the affected side. Twenty-one patients showed evidence of denervation, and 20 of these had an elevation of the taste threshold on the affected side. In nine cases the taste threshold was raised, while the facial nerve still responded to stimulation before degeneration had occurred.

Twenty-seven patients were seen more than 14 days from the onset of the palsy, and in this group the correlation between the normal taste response and a good prognosis was less clearcut.

This test allows the prognosis to be made on the first visit after the onset of Bell's palsy and is most accurate in the first 14 days. It is therefore useful to select patients who may require treatment from those who will make a full recovery spontaneously.

We are grateful to Drs. D. Taverner and J. L. James for their helpful guidance and for criticism of this work. We are indebted to Mr. B Harvey for construction of the apparatus. We thank all the general practitioners of the area for their co-operation in referring cases for this study.

\section{REFERENCES}

Cushing, H. (1903). Bull. fohns Hopk. Hosp., 14, 71. Denny-Brown, D., and Pennybacker, J. B. (1938). Brain, 61, 311. Garland, H. G. (1953). Medicine, edited by H. G. Garland and $W$. Phillips. Macmillan, London.

Krarup, B. (1958a). Acta oto-Laryng. (Stockh.), 49, 294. - (1958b). Ibid., 49, 389.

Langworth, E. P., and Tavener, D. (1963). Brain, 86, 465.

Moruzi, A., and Lechintski (1938). Rev. neurol., 70, 478.

Park, H. W., and Watkins, A. L. (1949). Arch. phys. Med., 30, 749.

Schwartz, H. G., and Weddell, G. (1938). Brain, 61, 99

Sullivan, J. A., and Smith, B. (1959). Proc. roy. Soc. Med., 52, 1083.

Taverner, D. (1955). Brain, 78, 209.

(1959). Proc. roy. Soc. Med., 52, 1077. 